\title{
O Megadesastre de Janeiro de 2011 na cidade de Nova Friburgo, Rio de Janeiro: aspectos históricos desde a colonização suíça e as condicionantes físicas
}

\author{
The January 2011 Magadisaster in Nova Friburgo, Rio de Janeiro: \\ historical aspects of Swiss colonization and the physical constraints
}

\author{
Priscila da Silva Cardoso $^{1} \&$ Rosemary Vieira ${ }^{2}$
}

\begin{abstract}
RESUMO
A região serrana do Rio de Janeiro sofreu intensamente com o desastre de Janeiro de 2011, onde fortes chuvas deflagraram uma série de deslizamentos e inundações. Esse estudo mostra como o fator antrópico potencializou historicamente tal evento na área central da cidade de Nova Friburgo. Para isso foi investigado e abordado o histórico da ocupação da localidade, em especial, a colonização suíça, pioneira na região. A cidade inicialmente construída pelos suíços às margens do rio Bengalas, e com o tempo, ocupada por outros imigrantes e habitantes de outras cidades, que passaram a instalar-se com mais intensidade sobre as ladeiras e no fundo dos vales, transformou-se em uma bomba relógio para as consequências dos eventos de elevadas precipitações. O desastre de Janeiro de 2011 a cidade é um exemplo desta perspectiva, uma vez que a ocupação de áreas consideradas de risco associada às intensas chuvas e às condições físicas regionais e trouxeram óbitos, perdas econômicas e ambientais.
\end{abstract}

Palavras chave: Imigração suíça, desastres naturais, deslizamentos, precipitação, Rio de Janeiro.

\begin{abstract}
The mountainous region of Rio de Janeiro suffered intensely due to the the disaster of January 2011, where heavy rains triggered a series of landslides and floods. This study shows how the anthropic factor has historically influenced the event in the central area of the city of Nova Friburgo. The story of populating of the city was investigated, especially the Swiss colonization, a pioneer in the region. The city was originally built by the Swiss immigrants along the Bengalas river, and ultimately became home to other immigrants and people from other cities, who mainly settled on the slopes and at the bottom of the valley. These areas have become a time bomb for the consequences of high precipitation events. The disaster of January 2011 in the city of Nova Friburgo is an example of this, the occupation of areas which are considered to be at risk during intense rainfall and the regional and local physical conditions which cause deaths, as well as economic and environmental damages.
\end{abstract}

Key-words: Swiss immigration, natural disasters, landslides, precipitation, Rio de Janeiro

Recibido el 04 de octubre de 2016. Aceptado el 24 de noviembre de 2011.

\footnotetext{
1 Depto de Geografia. Polo Universitário de Campos dos Goytacazes. Universidade Federal Fuminense. Rua José do Patrocínio, 71, Centro. Campos dos Goytacazes/RJ. priscilacardoso@id.uff.br

2 Laboratório de Processos Sedimentares e Ambientais (LAPSA). Instituto Nacional de Ciência e Tecnologia da Criosfera. UFF - Instituto de Geociências - Depto de Geografia. Av. Gal. Milton Tavares de Souza, s/n. Campus da Praia Vermelha. Boa Viagem - Niterói/RJ. rosemaryvieira@id.uff.br
} 


\section{INTRODUÇÃO}

As escarpas da Serra do Mar se estendem desde o estado do Espírito Santo até o norte de Santa Catarina, Brasil, compreendendo 1000 km de extensão (ALMEIDA \& CARNEIRO 1998). A disposição atual da Serra do Mar está relacionada aos processos de erosão, deslizamentos de encostas, fluxos de lama e de detritos, os quais originaram novas áreas, algumas com topografia suave. Devido à tais processos ao longo de milhões de anos, a Serra do Mar apresenta encostas naturalmente instáveis e muito suscetíveis a ocorrência de deslizamentos, como em todas as regiões tropicais úmidas do planeta (SANTOS 2004, 2008). As condições físicas, geográficas e geomorfológicas da Serra do Mar estão por trás de cenários de destruição, especialmente em áreas da Região Serrana do Estado do Rio de Janeiro, que historicamente pode revelar, por meio das cicatrizes nas encostas e movimentos de massa relictos, ainda que em áreas sem ocupação humana. Não obstante, o fator antrópico pode potencializar esses eventos. As ações sobre os terrenos naturais interferem na natureza geológica viva, que tem história, leis e processos dinâmicos próprios; uma vez desconsiderada manifesta buscando, a sua forma, recompor-se dos desequilíbrios a que lhe foram impostos (SANTOS 2012a).

Os eventos denominados desastres naturais que se sucedem no Brasil são, em sua maioria, de origem atmosférica. Entre esses, destacam-se as inundações, enxurradas, deslizamentos e secas que estão diretamente vinculados ao excesso ou ausência de chuva (MARENGO 2009). No Sudeste do Brasil, é frequente durante o verão a ocorrência das chuvas intensas que causam grande impacto na população.

Em áreas montanhosas de interface florestalurbana uma classe de desastre é aquela relacionada aos movimentos de massa. $\mathrm{Na}$ região Sudeste as áreas montanhosas ainda albergam remanescentes de ecossistemas florestados, porém em estágios distintos de sucessão vegetal e estados de conservação. Nessas áreas ocorrem sérios problemas com respeito ao uso do solo e a ocupação desordenada das terras, com reflexos nos impactos dos deslizamentos e inundações, desde séculos passados até os dias de hoje (NETTO et al. 2012).

Segundo as Nações Unidas, uma das mais impressionantes catástrofes climáticas no mundo se deu na Região Serrana do Rio de Janeiro, em 11 e 12 de Janeiro de 2011. A Região Serrana foi devastada bruscamente por chuvas intensas, com deslizamentos nas encostas, gerando perdas de milhares de pessoas, junto com os danos ambientais, sociais e econômicos (SILVA JUNIOR \& VIEIRA 2013).

De acordo com dados do INPE (Instituto Nacional de Pesquisas Espaciais) e da estação do INMET (Instituto de Nacional de Meteorologia), nos dias 11 e 12 de janeiro de 2011 foram registrados $166 \mathrm{~mm}$ de precipitação, mais de $70 \%$ da média histórica para o mês.

$\mathrm{O}$ desmatamento, primeiro fator antrópico para a construção de vivendas, caminhos, ruas e centros comerciais, com a ocupação irregular associada as precipitações extremas, tem levado a deslizamentos de encostas e inundações, que cobrou a vida de cerca de novecentos e cinco pessoas na Região Serrana, segundo dados do Banco Mundial (2012). As encostas com forte inclinação, impactadas pela intensa erosão do solo, o que se deve não somente pela eliminação da vegetação, como também às estruturas geológicas da área e a falta de planificação foi a principal causa das perdas relatadas anteriormente (PINHO et al. 2013).

A eliminação da vegetação tem um histórico no tempo e no espaço desde a chegada dos imigrantes suíços à cidade. A princípios do século XIX, mais precisamente em 1818, os primeiros imigrantes suíços estavam destinados ao Brasil para as terras que 
mais tarde se transformaram na cidade de Nova Friburgo, a fim de estabelecer una colônia (DUARTE 2009). Se se considera a geomorfologia/geologia da cidade de Nova Friburgo, pode-se inferir que os processos urbanos na cidade após a imigração e seu constante crescimento desordenado ao longo dos séculos seguintes foram um importante componente para o grande número de perda de vidas em janeiro de 2011 (GUERRA 2011).

Desta maneira, o presente trabalho consiste em demonstrar como o caráter físico associado a ocupação da cidade a partir da colonização suíça e ao longo dos séculos XIX e XX na cidade favoreceu a gravidade dos sucessivos eventos de inundação e deslizamentos, em especial o chamado Mega Desastre de Janeiro de 2011.

\section{MATERIAIS E MÉTODOS}

As metodologias utilizadas para a realização desse estudo consistem na investigação bibliográfica e fotográfica que buscam expor historicamente como a cidade foi transformada inicialmente pelos suíços e no recorrer dos anos e do contexto histórico, assim como a identificação das condições ambientais, com destaque para a área central da cidade. Foi localizada uma das primeiras plantas do município de Nova Friburgo, o que revelou configurações físicas da área central, das bases urbanas estabelecidas pelos suíços até os dias atuais. Considerando que foram realizadas pelos próprios colonos sem conhecimento da administração na época, essas bases urbanas podem ser consideras o marco inicial para o posterior crescimento da cidade, sem um planejamento adequado e continuo à suas configurações físicas (CORRÊA 2011).

As áreas centrais impactadas pela tragédia foram visitadas e foi realizada uma recopilação de dados secundários para a pesquisa, além da captura de coordenadas da região utilizando Google Earth (2015); mapas foram elaborados a partir de estudos do INEA (Instituto Estadual do Ambiente, Rio de Janeiro 2010) e do IBGE (Instituto Brasileiro de Geografia e Estatística 2013), com o uso do software disponibilizado gratuitamente Quantum Gis 2.8.

\section{Área de estudo}

Nova Friburgo possui uma área de 933.414 $\mathrm{km}^{2}$, segundo o IBGE (2010). Localiza-se a $22^{\circ} 16^{\prime} 55^{\prime \prime} \mathrm{S}$ y $42^{\circ} 31^{\prime}$ '52'W, no Estado do Rio de Janeiro. Apresenta um relevo acidentado com altitudes superiores a 2.000 $\mathrm{m}$; é um local de clima tropical de altitude (SILVA et al. 2011), na parte da Serra do Mar denominada Serra dos Órgãos. A Figura 1 apresenta a localização da cidade e o recorte da área de estudo.

A cidade possui características de relevo que a tornam suscetível aos eventos de precipitação intensa. Nova Friburgo apresenta um clima ameno que se torna mais seco a medida que se afasta da Serra do Mar, em direção ao interior do estado. Dados da Prefeitura de Nova Friburgo (2007) estimam uma de precipitação média anual de $2.000 \mathrm{~mm}$, sendo o período de dezembro-março os mais chuvosos e sujeitos a grandes índices de precipitação.

A área de estudo abarca a parte central da cidade, a partir do eixo sul-norte: Praça Marcílio Dias - Bairro Village e Rua Gal. Osório, passando pelas Praças Getúlio Vargas e do Suspiro, e a Avenida Alberto Braune. A Praça Marcílio Dias se destaca por sua localização na confluência dos rios Santo Antônio e Cônego, que formam o principal rio da cidade: o rio São João Bengalas.

\section{Geologia e geomorfologia de Nova Friburgo}

As características geológicas da Serra do Mar são representadas por duas províncias: ao sul o lineamento da falha de Cubatão, com rochas metamórficas antigas, e ao norte, rochas metamórficas mais recentes. 


\section{Localización del Área de Estudio}

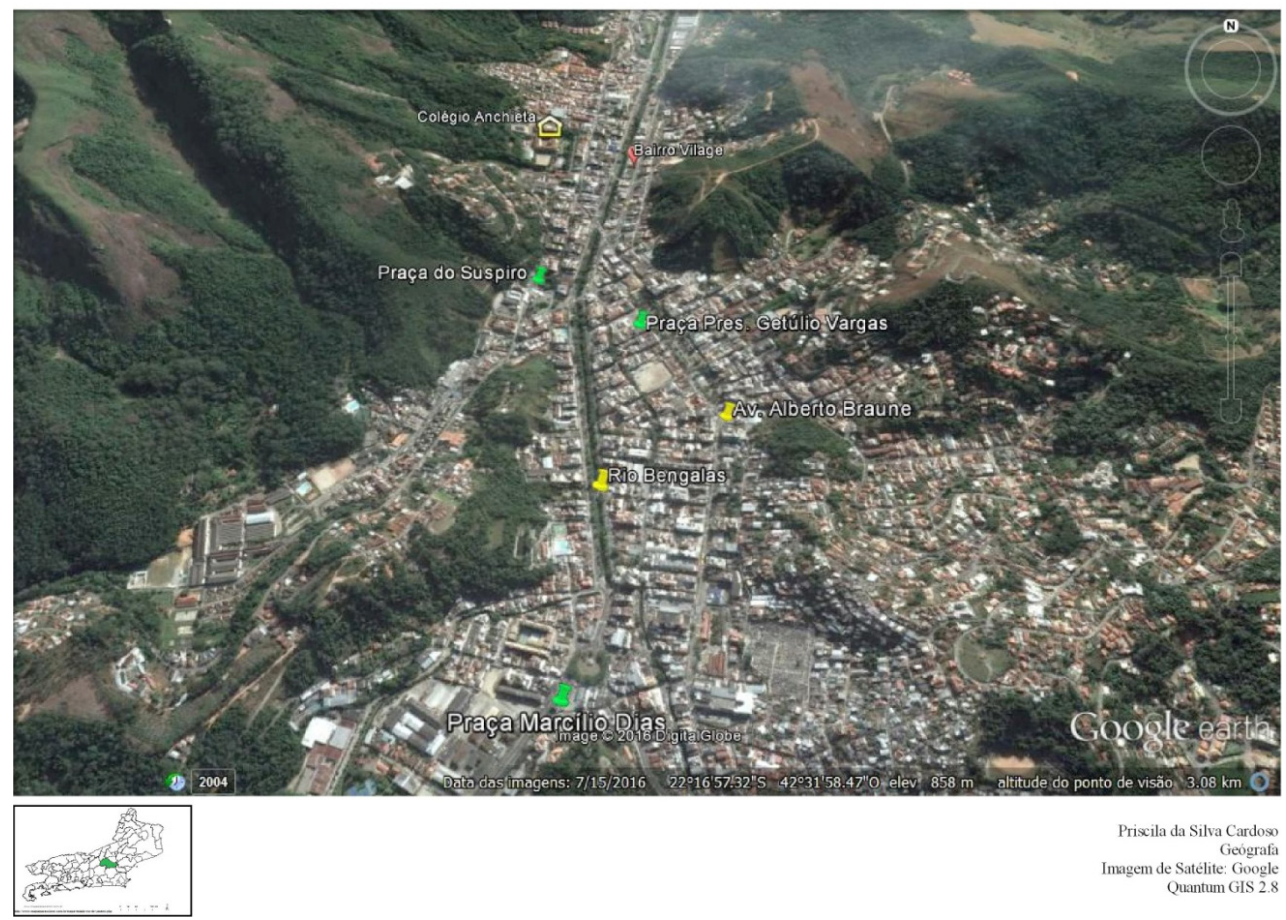

Fig. 1. Localização a cidade de Nova Friburgo.Fonte: google satélite -quantum gis (2016).

Fig. 1. Localization of Nova Friburgo city. Source: google satélite - quantum gis (2016).

Em ambas as províncias as rochas predominantes são: xistos, migmatitos e gnaisses (SANTOS 2008). Na região serrana de Rio de Janeiro predominam rochas ortoderivadas representadas por granodioritos característicos do Batólito Serra dos Órgãos e granitos homogêneos. Ainda são encontrados na região sedimentos quaternários de origem fluvial (INEA 2010). Constituído por rochas cristalinas graníticognáissicas pré-cambrianas (3.850-542 Ma) e paleozoicas (542-241 Ma), seu substrato rochoso é cortado por diques e intrusões básicas do Paleogeno (65 Ma). Essas rochas quase sempre apresentam sedimentos aluviais, coluviais e depósitos de talude. As vertentes com camadas de solos coluviais e depósitos de talude são mais suscetíveis às ocorrências de deslizamentos dessas coberturas nos períodos de maior pluviosidade, em geral entre os meses de dezembro e março (VOLOTÃO 2006).

A região de Nova Friburgo é parte integrante da classe de relevo conhecido como Mares de Morros, definida por Ab'SABER (2003) como domínio das regiões serranas, de morros mamelonares da parte Sudeste de Brasil, em área de climas tropicais e subtropicais úmidos, e dentro da zona da Mata Atlântica sul-oriental. A Figura 2 mostra o relevo da cidade, com poucas áreas planas e muitas áreas acidentadas. $\mathrm{O}$ relevo da cidade se caracteriza por feições quase retilíneas, com ladeiras escarpadas em forte desnível (VOLOTÃO 2006). Pináculos rochosos residuais também caracterizam seu relevo e seus níveis mais elevados atuam como divisores de água entre os rios que drenam em direção ao mar e os que 
drenam em direção ao norte, à bacia do rio Paraíba do Sul.

Com clima tropical quente e úmido, a região da Serra do Mar, apresenta um grande índice pluviométrico nas partes mais elevadas (SANTOS 2008): médias anuais de $4.000 \mathrm{~mm}$, sendo os meses de novembro a janeiro os com a concentração de chuvas mais elevada. De acordo com SANTOS (2008), tais características fazem da Serra do Mar uma área com suscetibilidade natural aos movimentos de massa: a combinação de fatores associados ao relevo (declividade das encostas), a pluviosidade, as características geológicas e a ação humana com o desmatamento propiciam eventos de deslizamentos na região serrana de Rio de Janeiro. As condições de declividade e tamanho das encostas propiciam a suscetibilidade de erosão dos vários ambientes (IBGE 2007). Áreas com predomínio de formas abruptas, usualmente ultrapassando 70\%, apresentam grande probabilidade de erosão, principalmente quando é considerado o regime de chuvas e quando tais encostas podem estar ocupadas (IBGE 2007).

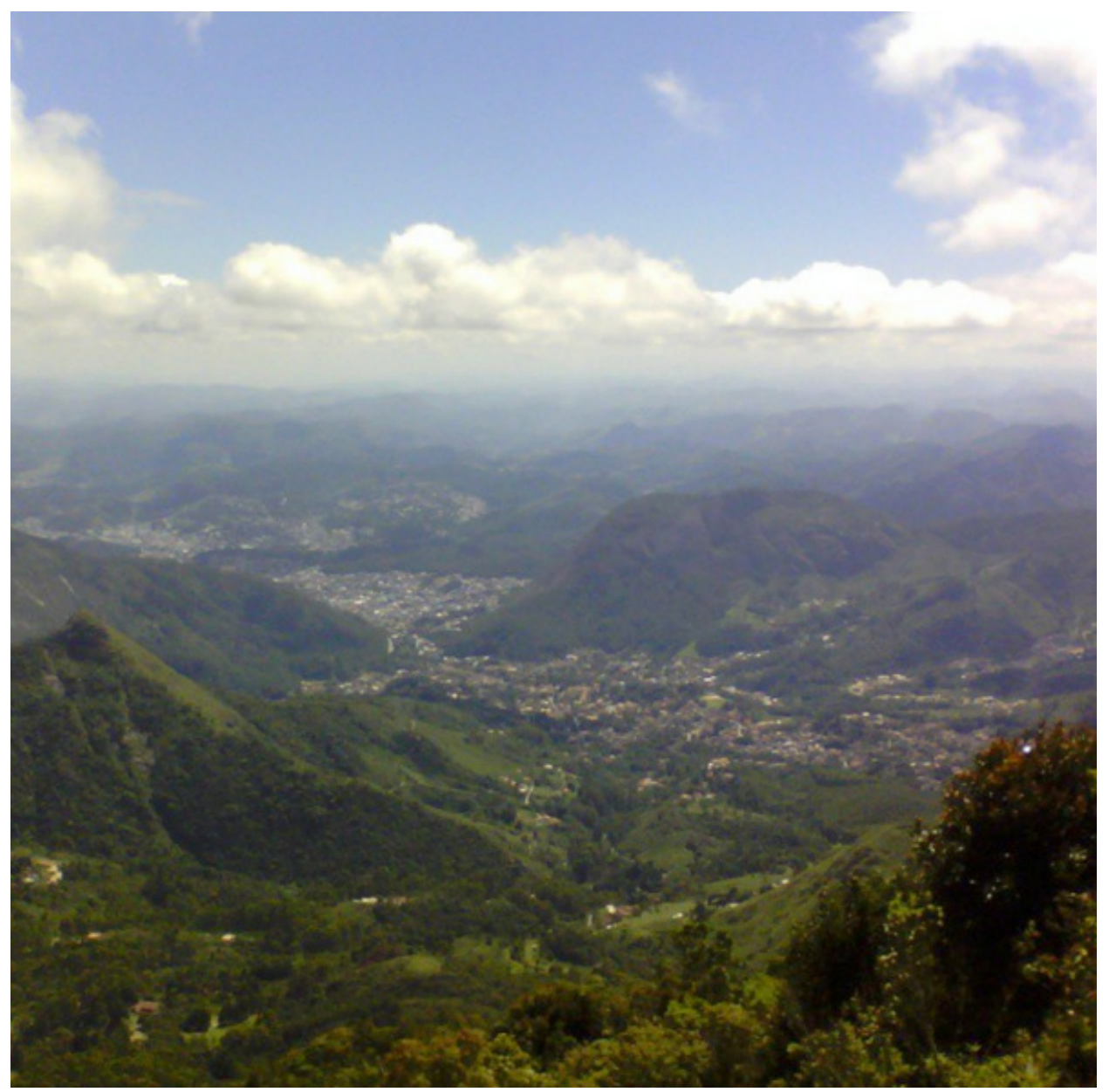

Fig. 2. Vista da cidade de Nova Friburgo desde o Morro Da Caledônia.

Fig. 2. View of the city from the caledonia peak. 
De acordo com o IBGE (2006), devido à natureza síltico-argilosa, o escoamento superficialéintenso, principalmente deáguas das chuvas de verão, que produzem além dos deslizamentos, erosão e acumulação de sedimentos no fundo dos vales. No caso de Nova Friburgo, dada às características do relevo já citadas, edificações realizadas em locais considerados inapropriados e aí se encontram encostas superiores a $30^{\circ}$ de declividade, a erosão é acelerada e intensa nos períodos chuvosos.

Segundo GUERRA \& JORGE (2013), os impactos dos processos que envolvem os movimentos de massa podem ser consequência direta do uso da terra e, nos casos extremos, constituir riscos a vida humana e edificações. No entanto, o fator antrópico representa a principal influência no agravamento dos riscos. Apesar dos fenômenos de chuvas de forte intensidade e deslizamentos serem mais propensos nas regiões tropicais, o aumento de áreas pelas atividades antrópicas, desencadeia reações, que associadas ao mau uso, manejo e conservação dos solos, vêm gerando problemas ambientais, principalmente em áreas de topografia acidentada (GUERRA et al. 2007). Portanto, chuvas concentradas, encostas desprotegidas de vegetação, contato solo-rocha abrupto, descontinuidades litológicas e pedológicas, declividade das encostas são algumas das condições que podem acelerar os processos erosivos (CUNHA \& GUERRA 2006), que juntamente com o manejo adequado podem acelerar a degradação (GUERRA et al. 2007).

De acordo com AVELAR et al. (2011), o fator que possibilita a estabilidade das encostas no Sudeste de Brasil, desde o Quaternário, é a densidade da cobertura florestal, que aumenta em épocas de temperatura e umidade mais elevadas. A cobertura vegetal e das florestas, assim como sua qualidade é um fator importante para evitar os processos de movimentos de massa. AVELAR et al. (2011) mencionam que a vulnerabilidade é originada cada vez mais pelo crescimento demográfico e ocupação das encostas, que degrada o ambiente a partir da retirada da vegetação.

Os tipos de movimentos de massa comuns na região serrana do Rio de Janeiro mostram características do tipo planar ou translacional e circulares ou rotacionais, acometidos em áreas e em ladeiras de elevadas inclinações e de solos pouco desenvolvidos. Os deslizamentos do tipo planar se caracterizam por solos de espessura e dimensões bem definidas com extensões maiores do que largura (SILVA et al. 2011). Esses tipos de deslizamentos estão relacionados a solos residuais sobre saprolitos, desfavoráveis a estabilidade.

Os movimentos de massa podem se ajustar ao que ROSS (2008) denomina de efeitos contrários, apesar de fazerem parte da dinâmica externa da superfície terrestre que interagem com outros fatores de meteorização e que modelam a paisagem (PINTO \& FREITAS 2012). Entre os fatores que contribuem para tal evento, a indução do campo de tensão gravitacional é o principal impulso para desencadear os deslizamentos associados a casos de grandes volumes de precipitação (SALGADO 2013). GUERRA \& JORGE (2013) destacam que os movimentos de massa são resultado da força de cizalhamento nas ladeiras, causadas pela gravidade, peso do material e água no solo que consegue superar a resistência dos materiais, determinada pelas propriedades de coesão dos solos nas vertentes. Um terreno propício a esse tipo de evento, aliado a interferência antrópica de forma irregular, pode deflagrar catástrofes de grandes proporções. As vertentes da Serra do Mar é um dos cenários más frequentes para tais eventos devido a: (a) elevada média de precipitação; (b) disponibilidade de cobertura de solo residual e camadas espessas de material coluvial sobre horizontes rochosos meteorizados (Figura 3); (c) diferenças de níveis naturais dos terrenos de cerca de $1000 \mathrm{~m}$ (ZNAMENSKY 
2014). Os principais impactos, em geral, a que os habitantes estão expostos são: (1) inundações, com pulsos de corrida de lama em áreas planas; (2) avalanches de detritos sobre casas e infraestrutura localizadas ao pé das ladeiras de forte inclinação e; (3) fluxo de detritos sobre cones coluviais (HUNGR 2014).

Ainda que com importantes características próprias de cada local e que devem ser levadas em conta, as enchentes e enxurradas que impactam um número maior de cidades brasileiras, e no caso especial, a região serrana do Rio de Janeiro, obedecem a uma equação hidráulica comum, segundo SANTOS (2012b): "volumes crescentemente maiores de água, em tempos sucessivamente menores, sendo escoados para drenagens naturais e construídas progressivamente incapazes de lhes dar vazão".

O maior aporte de águas pluviais para as drenagens decorre de uma cultura equivocada, pela qual as águas pluviais são consideradas um problema urbano, aplicando dessa forma a impermeabilização generalizada acompanhada da retificação e canalização dos cursos d'água. Como agravante, as drenagens naturais $\mathrm{e}$ construídas têm sua capacidade de vazão sensivelmente reduzida pelo assoreamento provocado por sedimentos originados de processos erosivos, entulhos e lixo urbanos (SANTOS, 2012b). Em casos extremos, o pico de cheia em uma bacia hidrográfica urbana pode chegar a seis vezes mais do que o pico dessa mesma bacia em condições naturais (PORTO et al. 2001).

A região serrana do Rio de Janeiro é, em função de seu relevo acidentado, caracterizada pelos eventos de enxurradas. Chuvas intensas e de curta duração aumentam intensamente a vazão, arrastando em muitos momentos a vegetação e as terras que compõem as suas margens (TUCCI 2007).

\section{Histórico da ocupação de Nova Friburgo e seus problemas}

Inicialmente, as terras que hoje correspondem a cidade de Nova Friburgo estavam subordinadas ao município de Cantagalo, sendo somente elevada à categoria de Vila em 3 de janeiro de 1820, alguns anos depois da chegada dos colonos suíços a localidade, quando foi desmembrada da Fazenda do Morro Queimado (CORRÊA, 2009).

Em sua obra Travels in the Interior of Brazil, o geólogo MAWE (1812) relata a ascensão dos caminhos por entre as barreiras montanhosas da Serra do Mar, em sítios que hoje correspondem a Nova Friburgo (Fazenda do Morro Queimado, assim denominado devido a cor escura das montanhas). No texto tece comentários sobre os caminhos em ladeiras muito estreitas e empinadas; chuvas fortes, relâmpagos e trovões; formações graníticas e gnáissicas; deslizamentos em partes das encostas vegetadas, e que por vezes, alcançavam os caminhos; muito barro, porém solos com camadas espessas de matéria orgânica.

Após as Guerras Napoleônicas, com a crise que a Europa enfrentava, uma das medidas tomadas pelos governos locais foi o deslocamento populacional para outras áreas, como o caso da Suíça (DUARTE 2009). Com as transformações econômicas mundiais no fim do século XVIII, em virtude da Revolução Industrial, a ampliação do contingente populacional foi qualificada como una maneira de atrair mão de obra e ocupar o espaço ocioso de determinadas regiões brasileiras. Sendo a imigração uma boa forma de preencher esses espaços, o rei D. João VI estabeleceu um projeto de povoamento suíço no Brasil (DUARTE 2009).

Por meio de um decreto, D. João VI em acordo com o Rincão de Fribourg, na Suíça, estabeleceu que cem famílias ocupassem as terras inóspitas até então da Vila 


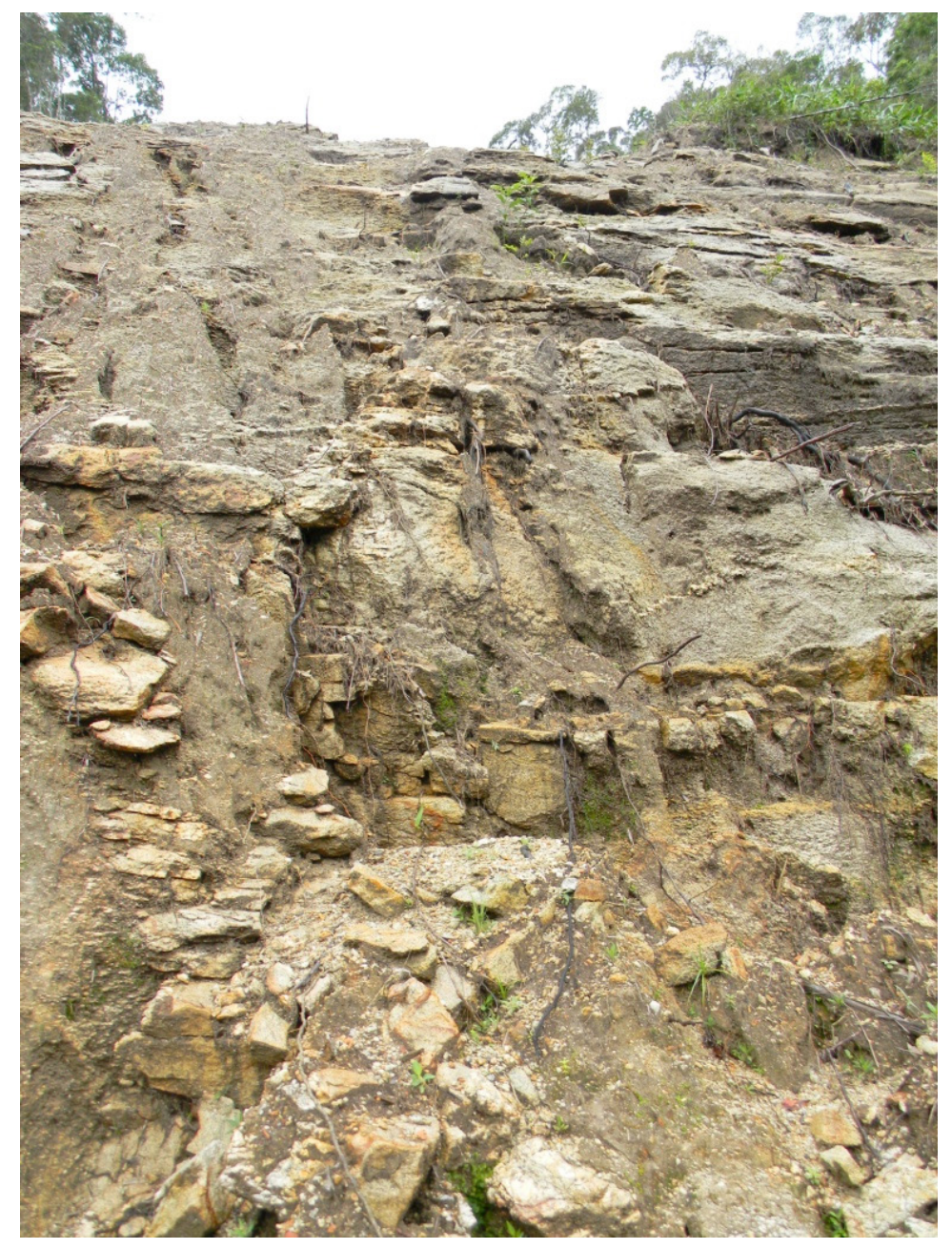

Fig. 3. Deslizamentos na vertente deixaram expostos os horizontes rochosos intemperizados.

Fig. 3. Landslides on the slope have exposed the weathered rocky layers.

Fribourg, assim nominada em homenagem a seus novos habitantes. Ao produzir as primeiras bases urbanas, os suíços também foram enviados pelo interesse português em ocupar a região, que na época era próxima a capital de Brasil, Rio de Janeiro (CORRÊA 2011). Era a primeira colônia não-lusitana instaurada no Brasil. Em seu trajeto até as terras do "Morro Queimado", os imigrantes enfrentaram desfiladeiros de mais de $1000 \mathrm{~m}$, as péssimas condições dos caminhos, agravadas pelas chuvas fortes de 1819; muitos perderam sua vida pelas enfermidades contraídas durante a travessia do oceano e pelas febres ao cruzar as áreas palustres antes da subida da serra (NICOULIN 1996; CORRÊA 2011).

Para assegurar residência e terras de plantio aos novos habitantes, foram designados dois sítios concebidos por títulos. A princípio se planificou a chegada de uma centena de famílias da Suíça à localidade, não obstante, duzentas famílias desembarcaram 
no Rio de Janeiro e chegaram à vila dez dias depois. Com uma centena de famílias a mais do que o esperado, ocorreu uma série de complicações: as residências ficaram aglomeradas de pessoas pela falta de outras vivendas (CORRÊA 2011). Com o verão, estação chuvosa, os terrenos se alagavam e as casas se enchiam de lama. Não havia canaletas nem escoamento de água; as poucas pontes eram muito frágeis. Portanto, os avanços públicos tiveram que ser providenciados pelos próprios colonos, ainda que os deslocamentos e construções requeressem a permissão da administração da época (CORRÊA 2011).

A hidrografia definiu inicialmente a localização do núcleo urbano, edificado às margens do rio Bengalas, na confluência dos rios Cônego e Santo Antônio (NICOULIN 1996; DUARTE 2009). Seguindo o eixo longitudinal do rio Bengalas, a ocupação suíça se deu nos vales estreitos e de paredes verticais de rochas sem vegetação; nos arredores das principais praças da cidade nas décadas seguintes à colonização, apesar das inundações dos rios nos meses de verão.

Registros da Fundação D. João VI de Nova Friburgo - Arquivo Pró-Memória testificam que muitos trabalhadores chegaram em seguida vindos de outros estados, com a tarefa de constituir a vila de Nova Friburgo, que se configurou da seguinte maneira: na margem oeste do rio Bengalas, foi construído o prédio do Administrador e de seus empregados. Segundo ARAÚJO (2003), na margem leste do rio Bengalas se configurou o restante da colônia, dividindose em três núcleos: (1) um próximo ao rio Santo Antônio em torno de uma praça retangular, a que hoje é chamada de Praça Marcílio Dias; (2) um segundo núcleo se encontrava mais ao norte, na parte central da vila, com quarenta e oito residências ao longo de um outro grande retângulo, o que hoje é a Praça Presidente Getúlio Vargas; (3) o terceiro se encontrava na área onde hoje está o bairro Vilage.
A Praça XV, posteriormente Praça Presidente Getúlio Vargas, era considerada o coração da cidade (ARAÚJO 2003). Na planta elaborada por Rubtsov, de 1820 (CENTRO CULTURAL DO BANCO DO BRASIL, 2010), representada na Figura 4, são marcados os quatro setores de ocupação da área central, que foram de suma importância para a configuração atual do centro da cidade.

Externamente aos núcleos urbanos, os terrenos destinados à agricultura estavam centrados em áreas mais elevadas e de difícil acesso, apesar a ser pouco propícias a ditas atividades (DUARTE 2009). O desmatamento era realizado nos meses de maio a julho (mais secos) e toda a vegetação era queimada. Eram escolhidos os terrenos com exposição oriente (NICOULIN 1996), no entanto, esses eram os que se localizavam nos setores de vertentes mais inclinadas. A retomada da mata de pequeno porte em um terreno abandonado tardava de 4 a 5 anos, e a de grande porte, de 12 a 15 anos (NICOULIN 1996). Poucos anos após o início da colonização já eram observadas consequências do desmatamento: os terrenos sem a vegetação eram impactados pelos ventos fortes, chuvas e geadas. Com a perda da camada espessa de despojos de vegetação que o protegia, o solo passou ficar em grande parte estéril (CORRÊA 2011).

A adaptação dos colonos às novas terras para o cultivo, diferente daquelas a que estavam acostumados, os impediu de aplicarem as técnicas que já conheciam e tiveram que adaptar-se a outros métodos de pecuária e cultivo. As primeiras colheitas dos colonos fracassaram por causa das chuvas constantes e intensas, além das inundações; o rio São João Bengalas transbordava, destruindo as casas, pontes e o rudimentar comércio; rochas rolavam desde os morros; árvores eram arrancadas. (NICOULIN 1996; CORRÊA 2011). Muitos colonos deslocaram-se por isso para as áreas circunvizinhas. Assim, com a mudança dos 


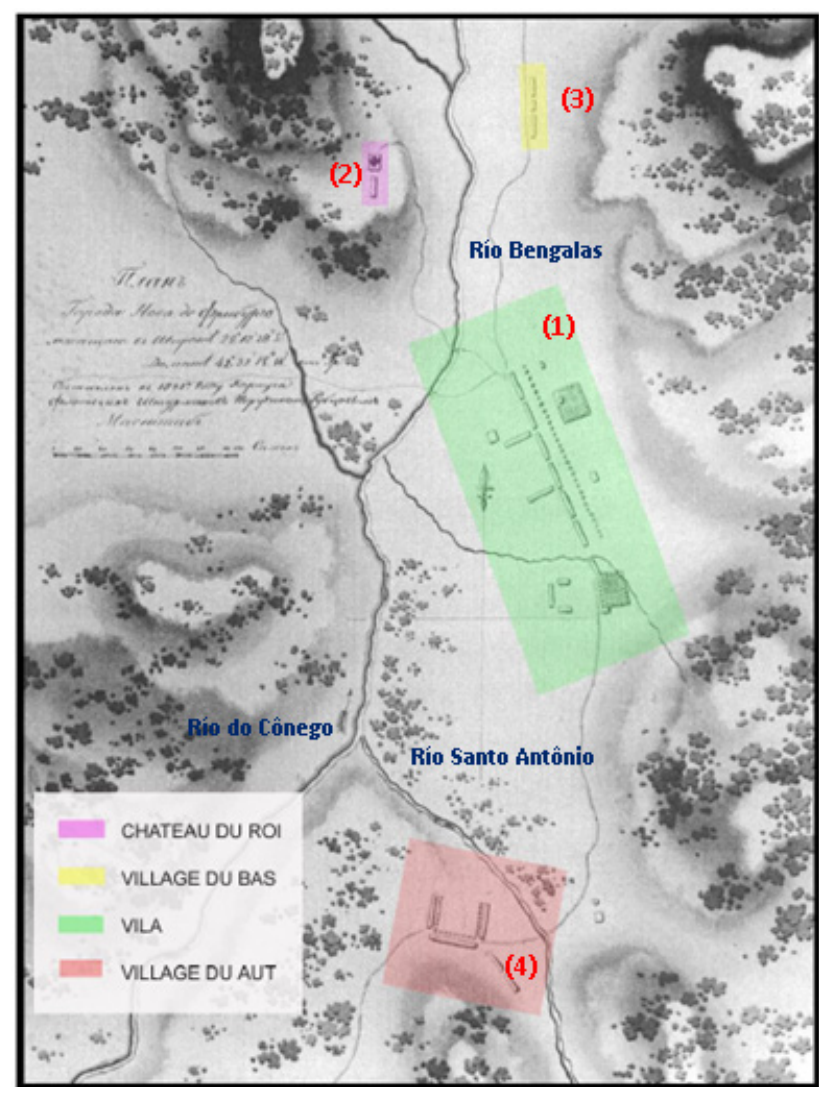

Fig. 4. Configuração do centro da cidade em 1820 por rutstov, com a compartimentação da vila em quatro partes: (1) casas de alguns colonos próximas a atual praça Getúlio Vargas; (2) a noroeste onde se encontra o atual colégio anchieta (antigo chauteau du roi); (3) a nordeste, a antiga village du bas, onde hoje se localiza o bairro vilage; (4) e, ao sul, o sítio onde foram instaladas as primeiras casas alrredor da praça chamada village du aut, atual praça marcílio dias. Fonte: Centro cultural banco do brasil 2010).

Fig. 4. Central village configuration in $\mathbf{1 8 2 0}$, with identification of four major areas: (1) some settler's houses next to the present getúlio vargas square; (2) northwest settlement, where is the current anchieta school (ancient chateau du roi); (3) northeast, the ancient village du bas, where today is found the vilage neighbohood; (4) southern area, the site where was implemented the first houses around the village du aut square, present Marcílio Dias square. Source: Centro cultural banco do brasil 2010).

colonos para outras partes, a colonização suíça fracassou, permanecendo apenas 701 indivíduos em 1839. O problema somente é em parte remediado com a chegada dos imigrantes alemães (CORRÊA 2011).

Em 1830, o centro da vila e o bairro Paissandú (com a Praça Marcílio Dias) já se apresentavam bem constituídos, com a parte plana densamente ocupada, agora também por imigrantes alemães. Com a expansão das atividades agrícolas centralizadas no café e após a instalação das primeiras fábricas, as encostas foram aos pouco tomadas para as construções de vivendas (DUARTE 2009; GUERRA 2011), sendo as das áreas vizinhas ao bairro Vilage e Colégio Anchieta as mais 
intensamente ocupadas. Em 1860 o rio Bengalas foi retificado e a expansão urbana passa a acompanhar esse eixo (Fig. 5). A expansão da cidade após 1870 , com a instalação das linhas férreas, que recebeu mão de obra das cidades vizinhas e, anos mais tarde, com a implantação de fábricas, por outros imigrantes, produziram um crescimento da cidade de forma desorganizada. Este feito associado a geomorfologia e à geologia, além das chuvas intensas, trouxe problemas ao bem-estar social, ambiental e econômico (CORRÊA 2011).

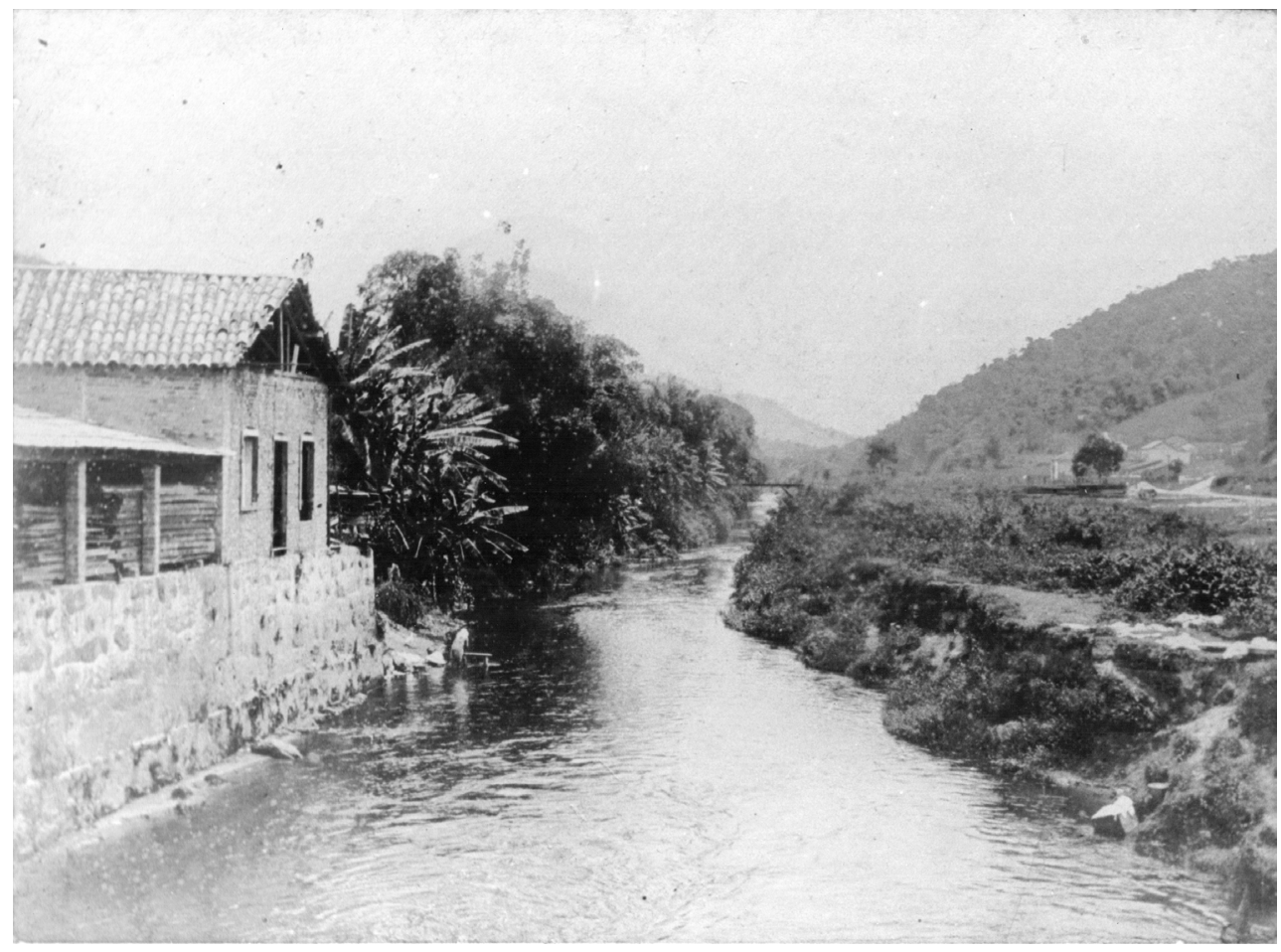

Fig. 5. Rio bengalas em 1898. Já se observa nessa época construção dentro do leito do rio, prática que se manteve até os dias atuais. Fonte: Fundação D. João Vi De Nova Friburgo arquivo pró-memória.

Fig. 5. Bengalas river in 1898. At this time construction is observed on the riverbed, which is kept until the present-day. Source: Fundação D. João Vi De Nova Friburgo - arquivo prómemória.

Em 1890 Nova Friburgo foi reconhecida como cidade, o que produziu grandes transformações territoriais no município. No fim do século XIX a cidade de Nova Friburgo já tinha uma ocupação urbana definida com a chegada de mais imigrantes: italianos, portugueses, espanhóis, libaneses e japoneses. A população se distribuía agora em grande parte pelo vale do rio Bengala, estendendo-se ao longo do eixo sul-norte.
Nessa época surgiu a Praça do Suspiro, o último espaço vazio da parte central da cidade, enquanto a atual Praça Marcílio Dias, já estava urbanizada (DUARTE 2009). A primeira área já estava impactada por grandes deslizamentos no início do século XXI (Figs. 6 e 7). A concentração da população em torno deste povoado do início da colonização suíça se converteu no centro da cidade. Novos caminhos foram 
abertos conectando aos novos bairros. Acomodações luxuosas e moradas muito simples passaram a dividiam o espaço na região central, promovendo tensões e reivindicações por parte da alta sociedade da época em busca de prosperidades urbanas (CORRÊA 2009).

Ao fim do século XIX e início do século $\mathrm{XX}$ o eixo de crescimento da cidade se expande em direção norte, no atual bairro de Conselheiro Paulino, também às margens do rio Bengalas, já retificado. Em 1873 foi inaugurado a estrada de ferro, conectando Nova Friburgo ao Rio de Janeiro, dando origem a outro eixo de expansão urbana e rompendo, dessa maneira o padrão dominado pelo rio Bengalas. Assim, com a diminuição do tempo de viagem entre Rio de Janeiro e Nova Friburgo, a cidade passou a receber mais visitantes pelo clima agradável da região (DUARTE 2009).
O século XX para Nova Friburgo marca um processo de industrialização forte, com parte da rede urbana consolidada. Indústrias dos setores têxtil, metal-mecânico e acessórios de couro se instalaram na cidade, junto com a chegada de mais imigrantes e de brasileiros de outras cidades e de outros Estados (DUARTE 2009). Essas indústrias claramente se fixaram em áreas já ocupadas, limitadas pelo relevo acidentado do vale, o que implicou numa concentração populacional em torno delas, o que levou à nova onda de ocupação dos morros próximos, estendendo assim a degradação não somente da natureza como também de sua paisagem (CORRÊA 2011).

Para a cidade de Nova Friburgo as primeiras décadas do século XX foram caracterizadas pelo desenvolvimento do polo industrial que atraiu moradores e trabalhadores desde cidades e regiões vizinhas. Foram deixados

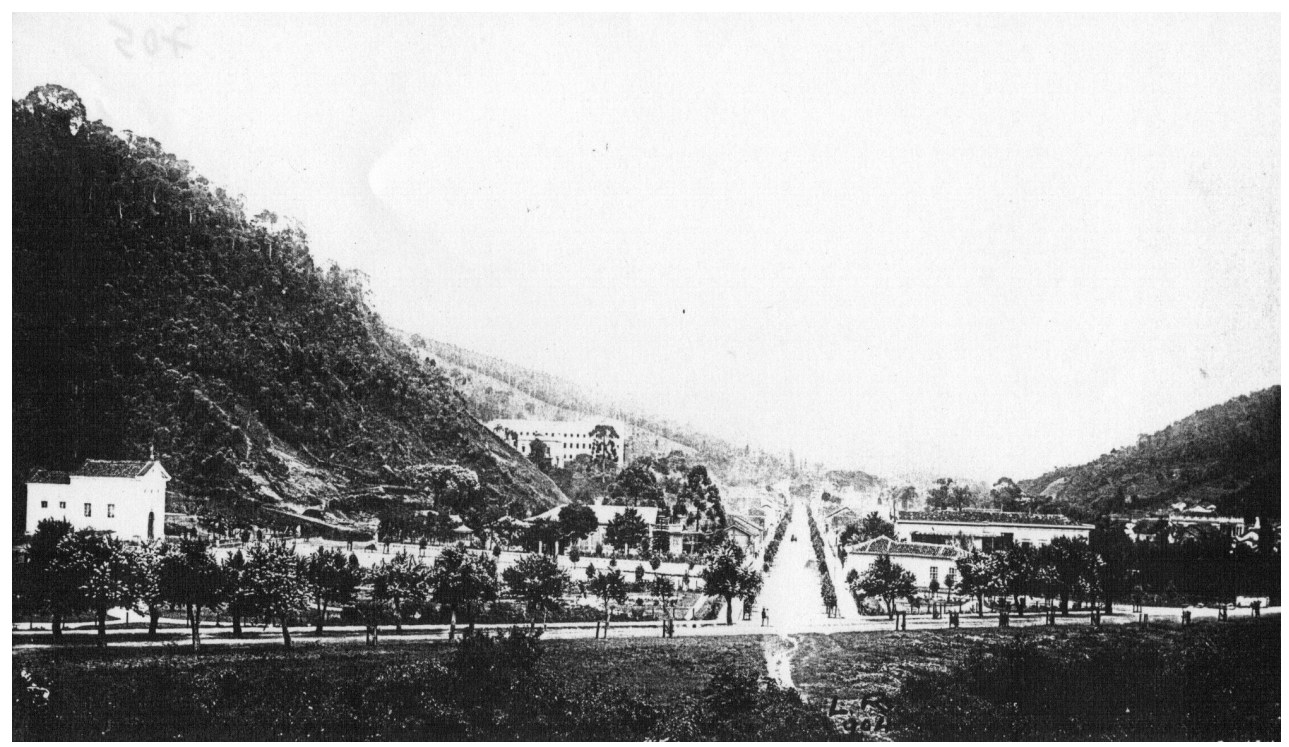

Fig. 6. Rua Gal. Osório em 1906. Grandes deslizamientos são observados próximos à igreja Santo Antônio (esquerda) e nas vencostas ao centro. Fonte: Fundação D. João Vi De Nova Friburgo - arquivo pró-memória.

Fig. 6. Gal, Osório street in 1906. Slides with notable scar are observed close to the church of Santo Antonio and in slopes at the central part. Source: Fundação D. João Vi De Nova Friburgo - arquivo pró-memória. 


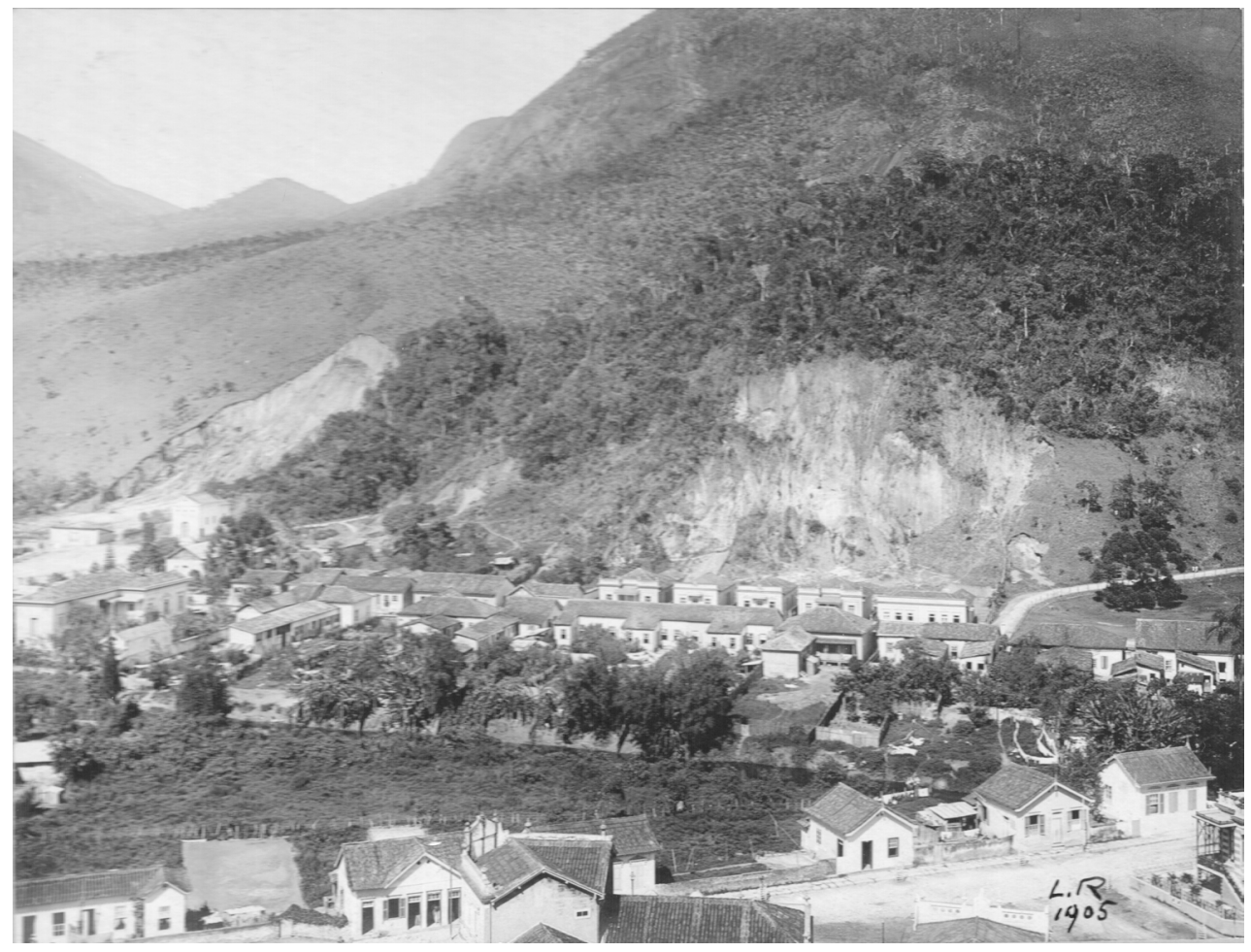

Fig. 7. Rua Gal. Osório em 1920. São observados o colegio anchieta (fundo à esquerda) e a praça do suspiro, em frente à igreja Santo Antônio. Ao pé da encosta, na direita da foto, se desenvolveu o bairro vilage, hoje ocupado por habitações até o cume dos morros. São observadas também as ladeiras já desmatadas. Este setor foi um dos mais impactados em janeiro de 2011. Fonte: Fundação D. João Vi De Nova Friburgo - arquivo pró-memória.

Fig 7. Gal. Osório street in 1920. Colegio anchieta (back and left) and suspiro square (in front of church of Santo Antonio). The vilage neighborhood was developed at the foot of the hills (right) and has spread on the slopes and summit of the hills. Deforested slopes are also observed. This sector was intensivelly impacted in 2011 january. Source: Fundação D. João Vi De Nova Friburgo - arquivo pró-memória.

de lado muitos dos aspectos naturais e do patrimônio público, alterando a imagem da cidade. Em 1930, por exemplo, o rio Bengalas, principal rio da região e um dos principais elementos de identidade da cidade, tinha somente pequenas partes de suas margens preservadas (DUARTE 2009).

De acordo com MALDONADO (2007), a vila inicial com duzentas e sessenta e uma famílias de colonos suíços se transformou, nas décadas de 1940 e 1950, em uma cidade de 12.390 habitantes a mais na área urbana e 3.845 na área rural. Desde então, Nova Friburgo perderia cada vez mais parte de sua cobertura vegetal, passando a sofrer intensa ocupação em suas encostas empinadas e dos leitos de seus rios. A industrialização crescente no século XIX deu início, na metade do século $\mathrm{XX}$, a verticalização da área central da antiga Vila Fribourg, principalmente nas áreas de comércio mais desenvolvido.

A marca do século XIX para o XX, assim como dos dias atuais, é a ocupação 
progressiva e a falta de controle por parte do poder público das encostas e do traçado plano que não comportaria o crescimento da cidade. Diferentemente da cidade de Petrópolis, também localizada na região serrana e que teve um plano urbanístico solicitado pelo governo imperial em meados do século XIX - Plano Köeler - (RABAÇO 1985; ASSUMPÇÃO 2015), Nova Friburgo não acompanhou esse processo, apesar de ter as condições necessárias para tal. Seus governantes não se preocuparam em fazer as reformas urbanas para o seu crescimento. Com melhorias urbanas realizadas apenas superficialmente, a cidade apresentava características ainda rurais, sem calçamento, iluminação pública digna e condições sanitárias básicas. MELNINXECO (2011) mostra o mapa de Rubtsov com as partes indicadas da Praça Getúlio Vargas, Praça Marcílio Dias, Bairro Vilage e áreas do Colégio Anchieta, ainda presentes na cidade nos dias de hoje. A Figura 8 apresenta essa configuração atual.

$\mathrm{O}$ grande abastecedor de água para Nova Friburgo, o rio Bengalas, foi não somente referência para os imigrantes, como também, condutor de tragédias e medo (ARAÚJO 2003). No início da

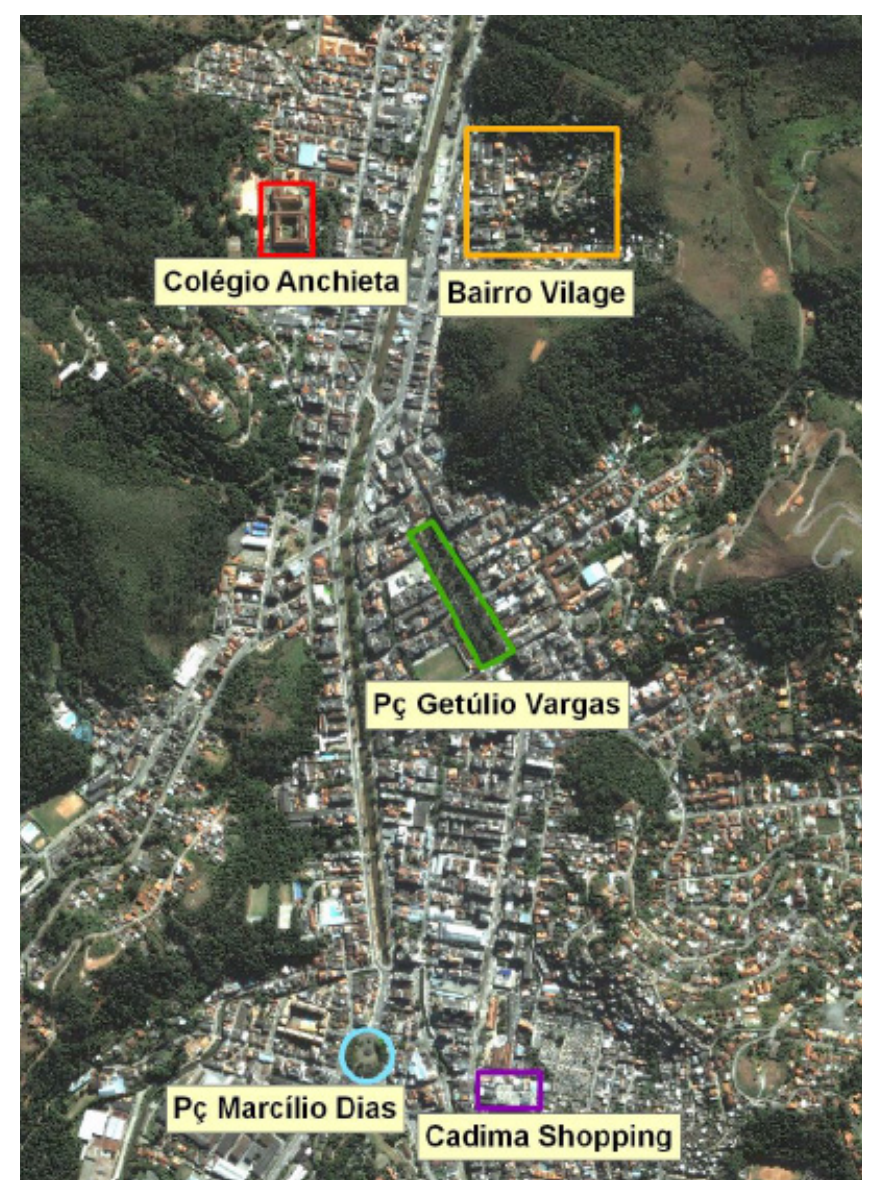

Fig. 8. Imagem da parte central de Nova Friburgo (QUICKBIRD, 2005). Fonte: MELNINXECO (2011).

Fig. 8. Image of the central area of Nova Friburgo (QUICKBIRD, 2005). Source: MELNINXECO (2011). 
colonização as enchentes do rio produziam extensas formações de áreas pantanosas e estancadas, ocasionando epidemias de febre amarela e a febre dos pântanos (CORRÊA 2011). As inundações seguiram por todos os séculos XIX e XX e ainda na primeira década do século XXI. A bacia do rio Bengalas possui forte concentração urbana e cada vez mais o uso de seu solo de forma inadequada, a concentração de atividades comerciais e a destruição da mata ciliar, estimularam um forte impacto ambiental, agravando-se quando chegam os meses de chuvas torrenciais, podendo engendrar ou potencializar as inundações e os movimentos de massa. Portanto, ao longo dos séculos XIX, XX e XXI, a expansão urbana em Nova Friburgo se caracterizou pela ocupação irregular e pela devastação dos morros, encostas e fundo dos vales e margens dos rios, sim antes da implantação dos sistemas básicos de infraestrutura.

No mapa de uso e cobertura atual do solo da cidade, na Figura 9, pode-se visualizar a grande ocupação urbana na região central, em áreas adjacentes ao rio São João Bengalas, principalmente em suas terras baixas, onde naturalmente o rio sofre as inundações. $\mathrm{O}$ vale de rio Bengala é simultaneamente, o principal elemento de desenvolvimento e de limitação da urbanização de Nova Friburgo, uma vez que sua obstrução pode estimular inundações e também a saturação do sistema viário principal (PLANO DIRETOR 1984). Nessas áreas a cobertura vegetal foi substituída por edificações que ocupam o interior do leito do rio.

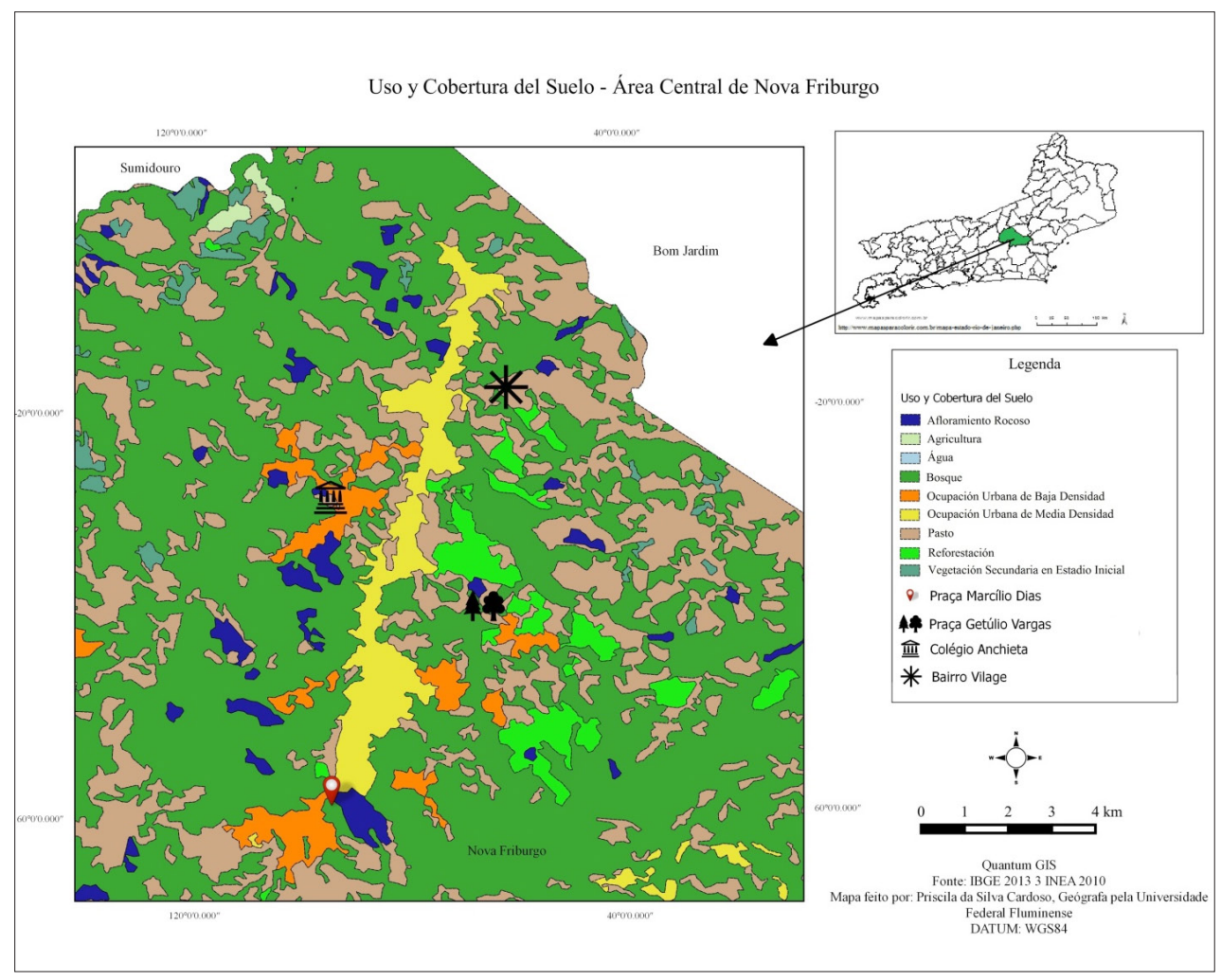

Fig. 9. Uso e cobertura do solo da parte central de Nova Friburgo.

Fig. 9. Land use of the central part of Nova Friburgo. 


\section{O desastre de Janeiro de 2011 e a ação antrópica}

Eventos de precipitação intensa ou extremas têm efeitos importantes sobre as sociedades, uma vez que associados aos deslizamentos e inundações, podem ser os mais destrutivos dos eventos extremos, em especial, em áreas da Serra do Mar no Sudeste de Brasil e na região serrana de Rio de Janeiro (MARENGO 2014).

Geralmente, a totalidade dos cenários de riscos de deslizamentos de solos e rochas e outras classes de movimentos de massa no Brasil estão relacionadas a formas inadequadas da intervenção do homem no meio físico-geológico, ocupando áreas que, por sua instabilidade natural, não deveriam ser ocupadas, ou ocupando áreas passíveis de ocupação, porém com técnicas inapropriadas (SANTOS 2012a). Foi o que ocorreu em janeiro de 2011 na cidade de
Nova Friburgo, onde inundações de grandes proporções, avalanches de lama e rocha e fluxos de detritos aconteceram no fundo do vale do rio Bengalas e em outros vales da cidade.

Nos dias 11 e 12 de janeiro, foram identificados mediante geoprocessamento o total de 2422 deslizamentos, em uma área total de $14,5 \mathrm{~km} 2$, segundo a Secretaria do Meio Ambiente de Nova Friburgo. A maior concentração dos movimentos de massa se deu nas partes altas das bacias hidrográficas; nas partes baixas das bacias, os danos e mortes, quase em sua totalidade, foram causados por enxurradas (DOURADO et al. 2012). Nas áreas rurais ocorreram a maior quantidade de deslizamentos, porém na área urbana o número de vítimas fatais foi significativamente mais elevado, devido, principalmente, a densidade da ocupação do solo (DIAS \& LIMA 2012). Dos registros de deslizamentos na Defesa Civil

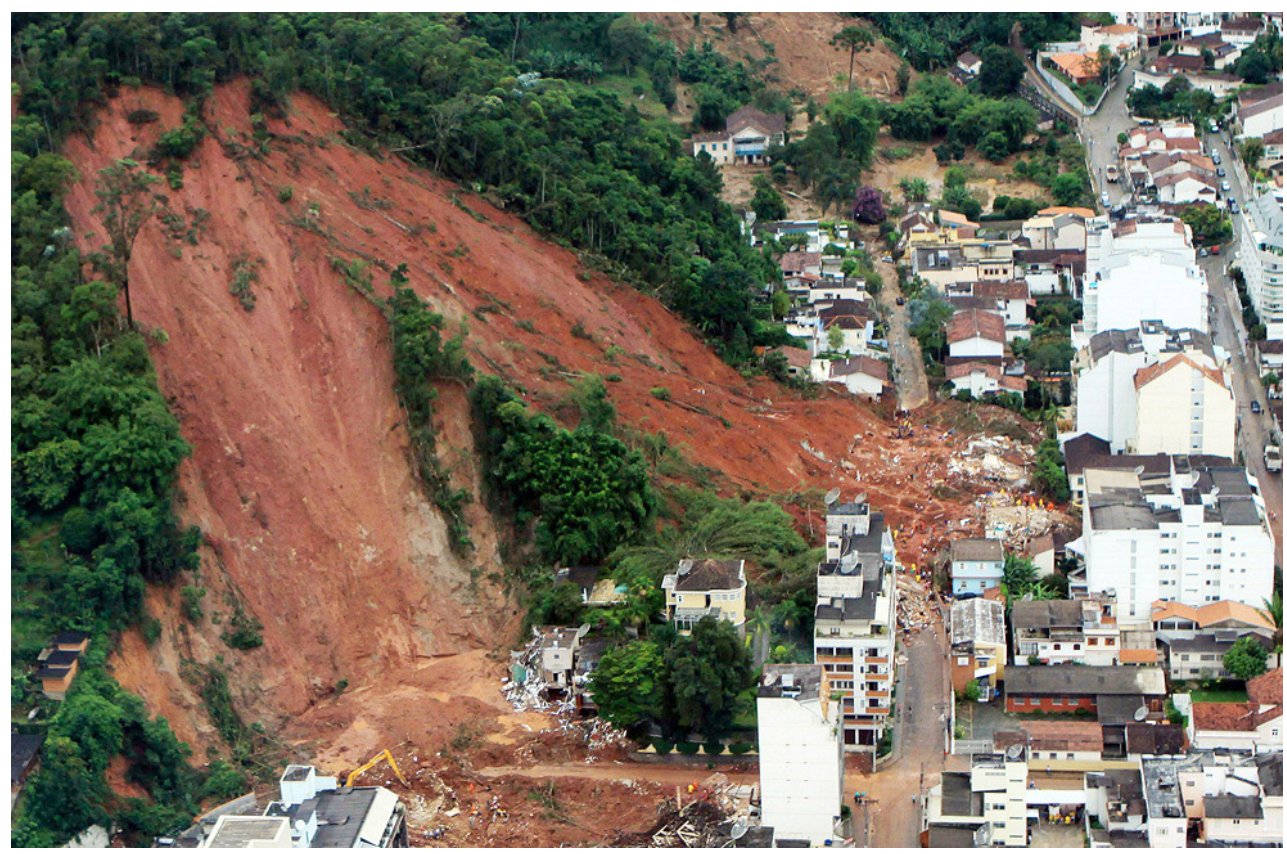

Fig. 10. Deslizamento do tipo planar no centro de Nova Friburgo. Foto: DRM. Serviço geológico do estado do Rio de Janeiro.

Fig. 10. Planar landslide in the downtown. Photo: DRM. Serviço geológico do estado do Rio de Janeiro. 
(PMNF 2011) 81\% se concentraram na área urbana: região central $(49 \%)$ seguido do bairro Conselheiro Paulino (32\%).

A Figura 10 identifica o deslizamento do tipo planar em solo com ladeiras de elevada inclinação no centro da cidade, em Janeiro de 2011. No local, ocorreu um número de mortes significativo e, todavia, há habitações nas laterais e na base da cicatriz do deslizamento, que apresentam risco iminente (CREA 2012). Todo o centro da cidade, seguindo o eixo do rio Bengalas e os morros que acompanham o vale, foi fortemente impactado. As praças do Suspiro e o bairro Vilage são outros exemplos de áreas de grande destruição no centro da cidade (Figs. 11 e 12).

Na Figura 12 pode ser observada uma característica comumente encontrada nas áreas urbanas da região serrana do Rio de Janeiro, como o observado por GUERRA et al. (2007) na cidade de Petrópolis, e que aumenta a degradação das encostas e o risco de deslizamentos: a via local transforma-se em escada, em seus pontos mais elevados, aproveitando dessa forma ao máximo o terreno.

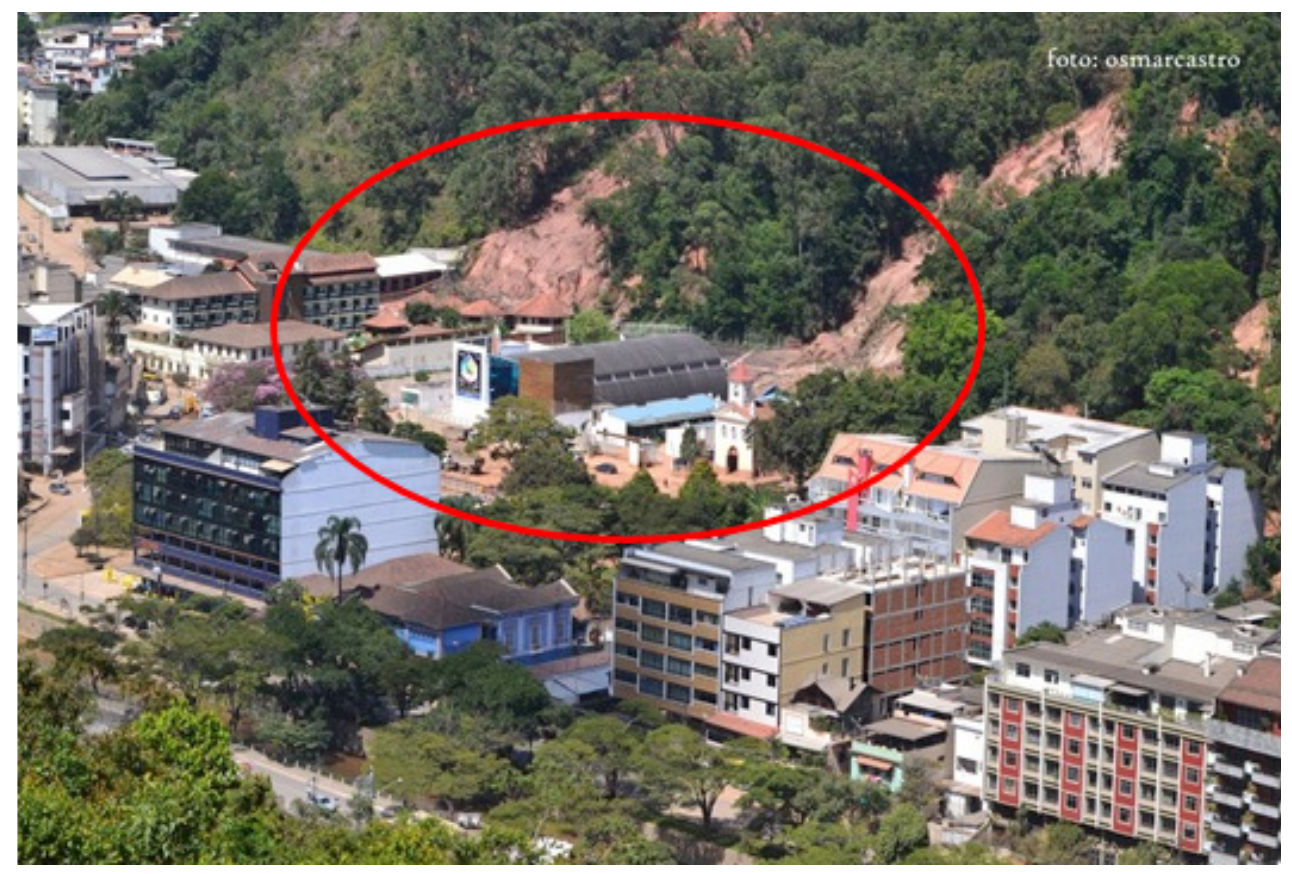

Fig. 11. Rua Gal. Osorio e praça do suspiro em Janeiro de 2011. Nota-se na área destacada em vermelho os deslizamentos sobre a praça do suspiro. Deslizamentos similares foram registrados em 1906 (Fig. 7). Foto: Oscar Prado.

Fig 11. Gal. Osório street and suspiro square in 2011 January. Note on red highlighted area the slides on the suspiro square. Similar slides were recorded in 1906 (Fig. 7). Photo: Oscar Prado. 


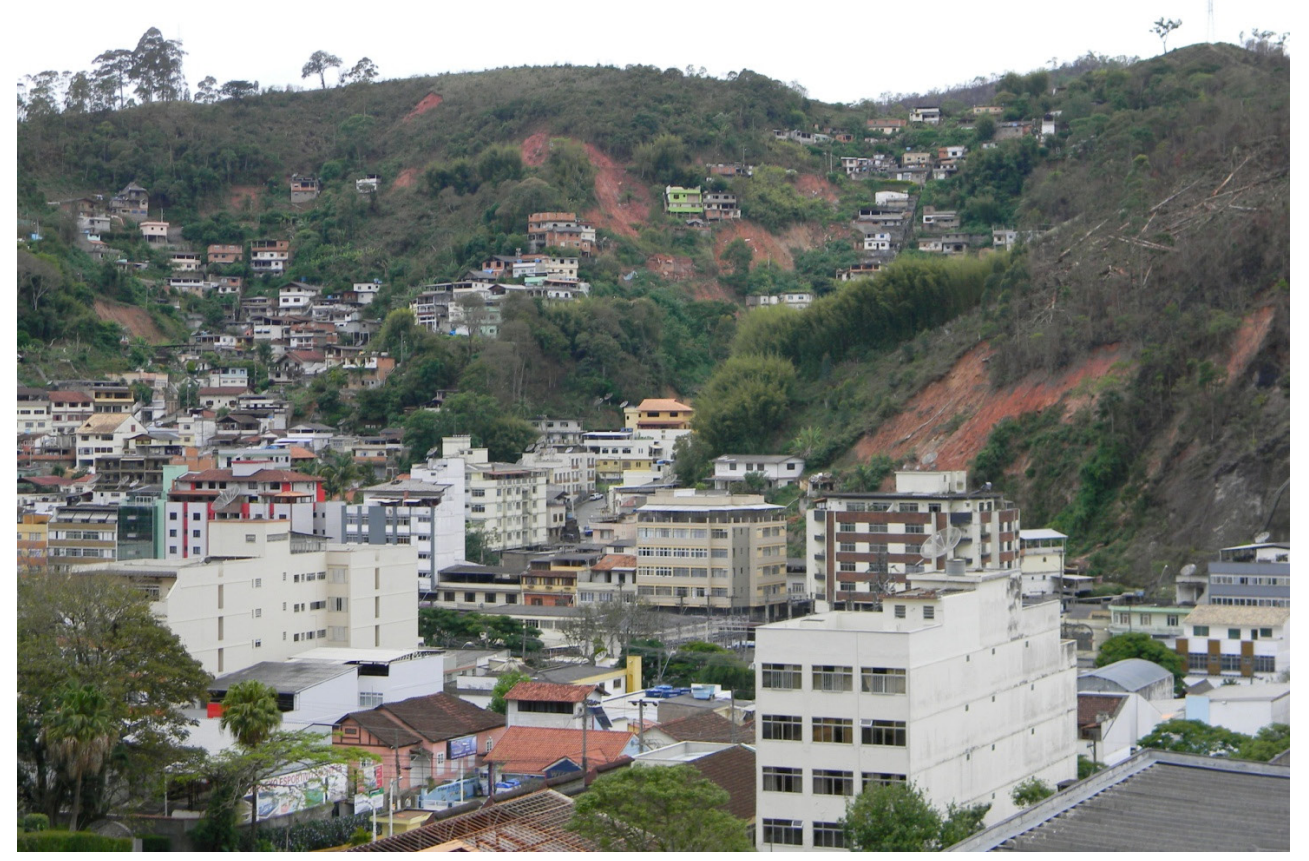

Fig. 12. Parte do bairro vilage meses depois do megadesastre de 2011. As vertentes empinadas são ocupadas até o seu cume por residências. Parte do acesso se dá por grandes escadas construídas pelo poder público, o que significa conivência e incentivo a ocupación de areas de risco de deslizamentos.

Fig. 12. Sector of vilage neighborhood after the 2011 disaster. The steep slopes are ocuppied by residences. Part of access to these areas is made by large stairs constructed by the municipality, which means the connivance and incentive to the irregular occupation in landslide risk areas.

$\mathrm{Na}$ semana que antecedeu o desastre em Nova Friburgo a Zona de Convergência do Atlântico Sul atuava sobre a região serrana do Rio de Janeiro e trouxe para a cidade de Nova Friburgo, em menos de seis horas, a precipitação necessária para ultrapassar o nível de inundação do rio Bengalas e a chuva esperada para o mês de janeiro inteiro. Do dia 11 para o dia 12 de 2011 a precipitação teve seu maior pico às três horas da manhã, quando os movimentos de massa e as inundações devastaram a cidade. No dia 12 os picos de precipitação foram os mais elevados às cinco da manhã e de sete às nove da manhã. A força das chuvas foi o suficiente para alterar o curso dos rios, desestabilizar as vertentes e originar uma nova geografia.

Para o CREA-RJ (2011) esse índice elevado de precipitação foi o componente deflagrador para os deslizamentos e para $o$ transbordamento dos rios, sendo os fatores predisponentes a geologia, geomorfologia e características morfométricas das bacias hidrográficas da região. Relacionando ditos fatores a antropização das bacias hidrográficas, essa tem sido causa agravante para a referida tragédia, uma vez que o desmatamento, a impermeabilização do 
solo e a ocupação desordenada em grande parte da bacia hidrográfica elevaram o escoamento superficial nas vertentes, gerando erosão. Esses processos agravaram os riscos de transbordamento hídrico e de deslizamentos das encostas, especialmente em vertentes com elevado grau de inclinação que é considerado inabitável. Informe do IBAMA (2011) sobre as chuvas em Nova Friburgo em janeiro de 2011 e suas consequências infere que cerca de 70 a $80 \%$ dos deslizamentos tiveram as ações humanas como coadjuvantes, em seus mais distintos graus de intervenção.

Entre os setores que sofreram perdas no evento de 2011, o habitacional apresentou cerca de 55\%, devido ao custo das obras de contenção das encostas, de outras medidas de redução da vulnerabilidade e do programa de reassentamento das famílias afetadas pelas inundações e deslizamentos (BANCO MUNDIAL 2012). Segundo o Banco Mundial (2012), R\$ 2 bilhões foram estimados para as perdas na região, sendo 1,7 bilhões concernentes a custos de adequação das margens, dragado dos rios e obras de contenção das encostas.

O informe do CREA de 2012 revelou que após um ano do desastre natural que atingiu a região serrana, o poder público limitou o atendimento às vítimas, deixando de lado a recuperação efetiva das áreas afetadas. Muitas áreas seguem muito vulneráveis a deslizamentos, os rios com lama indicam grande aporte de sedimentos provenientes da erosão dos solos ao longo de toda a bacia hidrográfica, com um grau elevado de desmatamento e de degradação ambiental.

As alterações no meio ambiente ao longo do tempo afetaram o bem-estar social, a economia e o próprio meio ambiente. As inundações constantes do rio Bengalas com danos materiais desde o início da colonização não despertaram nas autoridades ações de prevenção ou de ordenamento da ocupação. Ao contrário, o centro econômico, as melhores residências e as praças seguiram o eixo do rio. Segundo CORREAA (2009), no início da colonização, a própria Municipalidade estimulava a ocupação da área ao conceder pequenas parcelas a particulares. Os novos proprietários, por sua vez, eram obrigados a construir dentro de um determinado período e a pagar anualmente uma tributação aos cofres públicos. Ou seja, o estímulo da ocupação ao longo do rio era uma das principais fontes de renda da cidade.

Como pode ser observado nas figuras 7 e 10 , as ladeiras junto à igreja de Santo Antônio e ao longo da rua Gal. Osório já registravam grandes deslizamentos em 1906, e 105 anos depois, e ao longo desses anos outros grandes e trágicos deslizamentos se deram sem que o poder público se ocupasse de estudos realizados pelas universidades e institutos de pesquisas e das ações de prevenção, não somente na área, como em toda a cidade. Universidades vêm realizando ao longo das últimas duas décadas muitos estudos sobre o tema, porém o poder público não incluiu esse conhecimento no seu planejamento municipal e nas ações de prevenção, tampouco o Governo Estadual exigiu implementação de programa de controle e prevenção.

A ocupação em áreas de risco teve participação no desencadeamento de óbitos, perdas econômicas e ambientais, que perdura até hoje na região. Muitas dessas áreas ocupadas estavam em Áreas de Preservação Permanente (APP) ou dentro da faixa de 30 metros de distância da margem do rio, as quais, segundo o atual Código Florestal Brasileiro, deveriam ter a sua vegetação nativa preservada. De acordo com dados do BANCO MUNDIAL (2012), a cidade reportou 180.000 impactados, sendo $23 \%$ desses desabrigados. As erosões intensas causadas por esses eventos carregaram sedimentos que encheram $o$ sistema de drenagem urbana na parte mais baixa das encostas, aumentaram a turbidez das águas dos rios, e a sua consequente poluição, impactando negativamente a 
biodiversidade do ecossistema fluvial (CREA 2012). Sem contar na colmatação dos rios o que provocou a diminuição do escoamento hídrico, principalmente nos meses mais chuvosos.

\section{CONCLUSÕES}

As cidades, em geral, se desenvolvem às margens dos rios e não foi diferente em Nova Friburgo, com seu crescimento ao longo do rio São João das Bengalas. No entanto, desde o início da colonização, as inundações do rio e os deslizamentos das encostas com as chuvas torrenciais foram uma constante, quase anuais, exibindo a vulnerabilidade da cidade aos eventos meteorológicos e à ocupação não ordenada. A população e os governos conhecem tais processos desde séculos, não obstante não foi criado uma política ou cultura para seu enfrentamento e prevenção. Observase, portanto que os sistemas naturais são dinâmicos e nos quadros de referência e a coexistência da população com os fatores de risco desde o início do século XIX deveria ser gerado, ao longo do tempo, políticas e ações de fiscalização e ocupação ordenada da cidade, com desenvolvimento e emprego de tecnologias para a prevenção e administração de riscos.

O traçado urbano original da parte central de Nova Friburgo seguiu exatamente dentro das áreas de riscos naturais, como os geomorfológicos, já que esses acontecem independentemente da ação humana. A ocupação de novas áreas de risco prosseguiu com o tempo e insiste em manter-se nos dias atuais, não considerando o limite que tais áreas impõem, gerando em consequência, alterações drásticas na geomorfologia, hidrologia e na ecologia local.

A grande tragédia climática de 2011 assim como as tragédias anteriores não deveriam acontecer e tampouco atribuir a responsabilidade às mudanças climáticas, apesar da projeção de elevação do número de eventos extremos. No entanto, mesmo com grande número de ocorrências ao longo dos séculos, o Brasil e, em especial, a Região Serrana do Rio de Janeiro insistem em não estar preparados para enfrentarem as "catástrofes naturais", isto é, prevenção e preparação; tampouco mitigar os efeitos de um desastre com a ausência de planejamento frente a suas consequências. Em adição, o grande volume de recursos empregados em uma situação de tragédia, com a reconstrução de áreas destruídas e o trato com as populações castigadas, é muito maior do que se gastaria na prevenção.

A partir do exposto, foi possível verificar a importância das variáveis antropogênicas, em escala histórica, como um dos condicionantes de potencialização do evento de Janeiro de 2011, deflagrado pelo forte índice pluviométrico, que impactou não somente a cidade de Nova Friburgo, como toda a região serrana do Rio de Janeiro. A concentração da população em áreas de risco desde o início da colonização suíça, no curso do rio Bengalas e nas encostas, assim como as intervenções da urbanização no curso dos séculos XIX, XX e início do século XXI, com a retirada da vegetação, alteraram de maneira impactante os sistemas geomorfológicos e hidrológicos, o que revela uma série de lacunas históricas de desconsideração da dinâmica e escala dos processos naturais, o que demanda no presente e no futuro próximo ações completamente contrárias às que são exercidas atualmente pelos governos e pela população.

\section{AGRADECIMIENTO}

Ao Centro de Documentação D. João VI de Nova Friburgo pelas fotografias concedidas.

\section{REFERÊNCIAS}

AB'SABER, A. (2003). Os domínios de Natureza no Brasil: Potencialidades Paisagísticas. Ateliê Editorial, São Paulo. $153 \mathrm{p}$. 
ALMEIDA, F.F.M. \& CARNEIRO, C.D.R. (1998). Origem e Evolução da Serra do Mar. Revista Brasileira de Geociências, 28 (2), 135-150.

ARAÚJO, J.R. (2003). Nova Friburgo: A Construção do Mito da Suíça Brasileira. Tese de Doutorado, Universidade Federal Fluminense: 23-271. Recuperado de: $<$ http:// www.historia.uff.br/stricto/teses/Tese2003_ARAUJO_Joao_Raimundo_de-S. pdf $>$.

ASSUMPÇÃO, R.S.F.V.(2015). Petrópolis, um histórico de desastres sem solução? Do Plano Köeller ao Programa Cidades Brasileira. (246 p.) Tese de Doutorado, Fundação Oswaldo Cruz.

AVELAR, A.S., NETTO, A.L.C. \& D'ORSI, R.N. (2011). Monitoramento dos Problemas de Encosta da Cidade do Rio de Janeiro frente às mudanças climáticas futuras e em curso. GEOHECO, Lab. de Geo-Hidroecologia - Dept. Geografia UFRJ, Rio de Janeiro. Recuperado de: $<$ http://www.poli.ufrj.br/noticias/arquivos/ completo.pdf $>$.

BANCO MUNDIAL (2012). Avaliação de Perdas e Danos: Inundações e Deslizamentos na Região Serrana do Rio de Janeiro. Relatório elaborado pelo Banco Mundial, com o apoio do Governo do Estado do Rio de Janeiro. Brasília: 1-63. Recuperado de: $<$ http://www.mi.gov.br/pt/c/document library/get_file?uuid=74dde46c-544a-4bc4a6e1-852d4c09be06\&groupId=10157>.

CENTRO CULTURAL BANCO DO BRASIL (2010). Expedição Langsdorf. Brasília. (250 p.) Recuperado de:http:// www.bb.com.br/docs/pub/inst/dwn/ Langsdorff.pdf $>$.

CORRÊA, M.J.B. (2009). Histórias da História de Nova Friburgo. (pp.14-135). Educam. Nova Friburgo.
CORRÊA, M.J.B. (2011). Histórias e Memória de Nova Friburgo. (448p.) Rio de Janeiro: Educam.

CREA (2012). $3^{\circ}$ Relatório de Inspeção à Região Serrana do Estado do Rio de Janeiro. Recuperado de: $<$ http://www.crea-rj.org.br/ wp-content/uploads/2012/05/3o_relatorio_ chuvas 96DPI.pdf $>$.

CUNHA, S.B. \& GUERRA, A.J.T. (2006). Degradação Ambiental. In: Guerra, A.J.T. \& Cunha, S.B. (Orgs.). Geomorfologia e Meio Ambiente. (pp. 337-379). 6. ed. Rio de Janeiro: Editora Bertrand Brasil.

DIAS， L.F. \& LIMA， P.H.F. (2012). Mapeamento da espacialidade dos deslizamentos no município de Nova Friburgo - RJ. In: Simpósio Nacional de Geomorfologia 9, Rio de Janeiro, RJ. Anais. São Paulo: UGB.

DOURADO, F., ARRAES, T.C., \& SILVA, M.F. (2012). O Megadesastre da Região Serrana do Rio de Janeiro - as causas, os mecanismos dos movimentos de massa e a distribuição espacial dos investimentos de reconstrução pós-desastre. Anuário do Instituto de Geociências, UFRJ, 35 (2), 43-54.

DUARTE， F.R.P. (2009). Nova Friburgo: Um estudo sobre Identidade Urbanística. Dissertação de Mestrado, Universidade de Brasília. Brasília, (DF), 69-93. Recuperado de: $<$ http://repositorio. unb.br/bitstream/10482/4128/2/2009 FernandaReginaPereiraDuarte_capitulo_3. pdf>.

GUERRA, A.J.T. (2011). Geomorfologia Urbana. (280 p.). Bertrand Brasil, Rio de Janeiro.

GUERRA, A.J.G., GONÇALVES, L.F.H., \& P.B.M. LOPES (2007). 
Evolução histórico-geográfica da ocupação desordenada e movimentos de massa no município de Petrópolis nas últimas décadas. Revista Brasileira de Geomorfologia, 8 (1), 35-43.

GUERRA, A.J.T. \& JORGE, M.C.O. (2013). Processos Erosivos e Recuperação de Áreas Degradadas. (192 p.). Oficina de Textos, São Paulo.

HUNGR, O. (2014). Debris flow and debris avalanches; motion analysis. In LACERDA et al. (Eds). Extreme Rainfall Induced Landslides: an International Perspective. (pp. 87-102). Oficina de Textos, São Paulo.

IBAMA. Instituto Brasileiro do Meio Ambiente. Relatório da Tragédia em Nova Friburgo, 2011. Recuperado de: http://ibamanovafriburgo.blogspot.com. br/2011/02/relatorio-da-tragedia-de-nova. html.

IBGE. Instituto Brasileiro de Geografia e Estatística (2006). Recuperado de: $<$ http://cidades.ibge.gov.br/xtras/perfil. php?codmun $=330340>$ Acesso em: $21 \mathrm{de}$ outubro de 2015.

IBGE. Instituto Brasileiro de Geografia e Estatística (2007). Manual Técnico de Pedologia. Recuperado de: $<$ http:// biblioteca.ibge.gov.br/visualizacao/livros/ liv37318.pdf $>$.

IBGE. Instituto Brasileiro de Geografia e Estatística (2010). Censo Demográfico, Nova Friburgo. Rio de Janeiro. Recuperado de: $<$ http://cidades.ibge.gov.br/painel/ populacao.php? $\operatorname{codmun}=330340>$.

INEA. Instituto Estadual do Ambiente. Rio de Janeiro (2010). Recuperado de: $<$ http:// www.inea.rj.gov.br/cs/groups/public/ documents/document/zwew/mde1/ edisp/ inea0015448.pdf>
MALDONADO, G.P., MATOS, C.M. \& BRANCO, C.F.C. (2007). Agenda 21 Nova Friburgo: 2-60. Recuperado de: $<$ http:// agenda 21 comperj.com.br/sites/localhost/ files/Nova\%20Friburgo.pdf $>$.

MARENGO, J.A. (2009). Impactos de extremos relacionados com o tempo e o clima. Impactos sociais e econômicos. (pp. 1-4). Boletim do Grupo de Pesquisas em Mudanças Climáticas (GPMC), 8, Edição Especial, Instituto Nacional de Pesquisas Espaciais.

MARENGO, J.A. (2014). Variability and changes in rainfall extremes in Southeastern South America: observation and projected trends and potential social impacts. (pp. 25-37). In LACERDA et al. (Eds). Extreme Rainfall Induced Landslides: an International Perspective. Oficina de Textos, São Paulo.

MAWE, J. (1812). Travels in the Interior of Brazil. (409 p.). Longman, London.

MELNIXENCO, V.C. (2011). A Planta Mater: Expedição Langsdorff em Nova Friburgo. $1^{\mathrm{o}}$ Simpósio Brasileiro de Cartografia Histórica. Paraty. Recuperado de: <https://www.ufmg.br/rededemuseus/ $\mathrm{crch} / \mathrm{simposio/MELNIXENCO}$ VANESSA CRISTINA.pdf $>$.

NETTO, A.L.C., AVELAR, A.S., SATO, A.M., DIAS, M.A., SCHLEE, M.B., \& NEGREIROS, A.B. (2012). Vulnerabilidade em geoecossistema montanhosos e desastres causados por deslizamentos na interface florestal-urbana: controles geológicos, geomorfológicos e geoecológicos. (pp. 63-80). In LACERDA, W.A., PALMEIRA, E.M., NETTO, A.L.C., EHRLICH, M. (orgs). Desastres Naturais. COPPE/UFRJ, Rio de Janeiro.

NICOULIN, M. (1996). A Gênese de Nova Friburgo: emigração e colonização suíça 
no Brasil (1817-1827). (367 p.). Fundação Biblioteca Nacional, Rio de Janeiro.

PINHO, G.M., FRANCISO, C.N., \& SALGADO, C.M. (2013). Análise Espacial dos Movimentos de Massa em Nova Friburgo/RJ. O caso do Desastre Natural de Janeiro de 2011. Recuperado de: $<$ http:// www.e-publicacoes.uerj.br/index.php/ tamoios/article/viewFile/5355/5197>.

PORTO, R. (2001). Drenagem urbana. In TUCCI, C.E.M. (org). Hidrologia: ciência e aplicação. (pp. 769-847). Ed. UFRGS, Porto Alegre.

PINTO, R.W.P. \& FREITAS, M.M. (2011). Considerações a respeito dos movimentos de massa ocorridos em janeiro de 2011 na bacia do Córrego D'antas, Nova Friburgo, RJ. Revista do Departamento de Geografia da PUC-Rio. Rio de Janeiro, 5 (9), 79-96.

PMNF. Prefeitura Municipal de Nova Friburgo (2007). Recuperado de: <http://www.cidades.gov.br/images/ stories/ArquivosSNPU/Biblioteca/ PrevencaoErradicacao/Plano_municipal_ Nova_Friburgo.pdf $>$.

PMNF. Prefeitura Municipal de Nova Friburgo (2011). Recuperado de:http:// www.pmnf.rj.gov.br/dados_n.php>.

PMNF. Prefeitura Municipal de Nova Friburgo (2014). Decreto $\mathrm{n}^{\circ}$ 31, de 20 de Fevereiro de 2014. Recuperado de: $<$ http://media.wix.com/ ugddaef47_78016d5c1f574a4db2805cc3b 858b117.pdf $>$.

RABAÇO, H.J. (1985). História de Petrópolis. (140 p.). Petrópolis: Instituto Histórico de Petrópolis.

ROSS, J.L.S. (2008). Geomorfologia: ambiente e planejamento. (84 p.). $8^{\circ}$ ed. Ed. Contexto, São Paulo.
SALGADO, J.C.R.S.S. (2013). Avaliação e modelação da suscetibilidade a movimentos de vertente superficiais translativos em Nova Friburgo. $2^{\circ}$ Ciclo de Estudos em Sistemas de Informação Geográfica e Ordenamento de Território. Universidade de Letras do Porto. Recuperado de: $<$ https://repositorio-aberto. up.pt/bitstream/10216/68693/2/70824.pdf>.

SANTOS, A.R. (2004). A Grande Barreira da Serra do Mar: da trilha dos Tupiniquins à Rodovia dos Imigrantes. (122 p.). Nome da Rosa, São Paulo.

SANTOS, A.R. (2008). Diálogos Geológicos. (182 p.). Ed. Nome da Rosa, São Paulo.

SANTOS, A.R. (2012a). Carta geológica e carta de riscos: distinções no significado, na elaboração e no uso. (pp. 19-26). In LACERDA, W.A., PALMEIRA, E.M., NETTO, A.L.C., EHRLICH, M. (orgs). Desastres Naturais. COPPE/UFRJ, Rio de Janeiro.

SANTOS, A.R. (2012b). Enchentes e Deslizamentos: causas e soluções. (124 p.). Ed. Pini, São Paulo.

SILVA, F.B., MAIA, F.R.C., GREGÓRIO, R.S., \& ARAÚJO, R.C.L. (2011). Escorregamentos das Encostas da Região Serrana do Estado do Rio de Janeiro, Fenômeno denominado Debris Flow (Corrida de lama). Curso de Engenharia Civil da Universidade Anhembi Morumbi, São Paulo. Recuperado de: $<$ http:// engenharia.anhembi.br/tcc-11/civil-15.pdf $>$.

SILVA JUNIOR, J.F. \& VIEIRA, R. (2013). Variabilidad interanual de las precipitaciones en la Región Serrana de Rio de Janeiro, en el periodo 1971-2010. Investigaciones Geográficas Chile, 45, 1936.

TUCCI, C.E.M.(2007). Inundações Urbanas. (156 p.). Porto Alegre: ABRH/RHAMA. 
VOLOTÃO, C.N. (2006). Deslizamentos de Terra no Município de Nova Friburgo: Histórico e Interpretação Estatística dos Dados. Pós-Graduação em Modelagem Computacional. UERJ - Rio de Janeiro. Recuperado de: $<$ http://livros01.livrosgratis. com.br/cp021208.pdf $>$.
ZNAMENSKY, D.V. (2014). Debris and mudflow initiation processes in Brazilian tropical and subtropical humid and mountainous environments. (pp. 103-127). In LACERDA et al. (Eds). Extreme Rainfall Induced Landslides: an International Perspective. Oficina de Textos, São Paulo. 